(2) Open Access Full Text Article

\title{
Immunization Status and Challenges During COVID-19 and Associated Factors Among Children Aged 10-23 Months in South Region, Ethiopia 2020
}

This article was published in the following Dove Press journal:

Pediatric Health, Medicine and Therapeutics

\begin{abstract}
Alemnew Wale Tegegne (iD)
Aychew Kassie Gidafie ${ }^{2}$

Desalegn Girma Mamo Snr'

Semahegn Tilahun Wassie ${ }^{\prime}$

Zinie Abita Mengie'

'Department of Midwifery, College of Medicine and Health Science, Mizan Tepi University, Tepi, Ethiopia; ${ }^{2}$ Department of Nursing, College of Medicine and Health Science, Mizan Tepi University, Tepi, Ethiopia
\end{abstract}

Correspondence: Alemnew Wale Tegegne

Tel +25I918657367

Email walealemnew@gmail.com
Background: The worldwide COVID-19 pandemic is overstressing health systems and Essential health services and vaccination services are disrupted. Immunization is a confirmed gizmo for governing and even eliminating communicable diseases.

Objective: This study aims to assess the challenge and status of immunization during COVID-19 and associated factors among children aged 10-23 months south Nation Nationality and People Region Ethiopia. Methods and Materials: community-based mixed quantitative and qualitative cross-sectional study was done in southwest Ethiopia. Data was collected using semi-structured questionnaires and in-depth interviews. After that, the data were edited, coded, and move in into Epi info version 7.2 for data management then transported to SPSS version 25 for analysis. The analyzed data were presented by tables, graphs, figures, and text form.

Results: According to this study, the prevalence of incomplete immunization was found to be $809(62.2 \%)$ with $(95 \%$ CI: 59.5, 64.8). In multivariable analysis waiting time at a health facility ( $\mathrm{AOR}=0.04,95 \% \mathrm{CI} 0.0001,0.004)$, education ( $\mathrm{AOR}=5.08,95 \% \mathrm{CI} .31,11.14)$, place of delivery $(\mathrm{AOR}=2.34,95 \% \mathrm{CI} 4.96,6.089)$, fearing of COVID-19 (AOR=3.62,95\% CI $1.72,7.64)$ and do not understand the separation care of COVID-19 and other health services $(\mathrm{AOR}=2.85,95 \% \mathrm{CI} 1.38,5.9)$ were significantly associated factors

Conclusion: The prevalence of incomplete immunization among children aged 10-23 months was very high in this study as compared to the other studies done in a different pocket of Ethiopia. Consecutively, reducing waiting time at a health facility, avoiding unnecessary fear of COVID-19, and promoting immunization in a different area of southwest Ethiopia along with health extension workers are recommended.

Keywords: immunization status, challenge, children 12-23-month-old, southwest Ethiopia

\section{Background}

COVID-19 is one of the main pathogens that primarily target the human respiratory system. At end of December 2019; a mass of patients were admitted to the health facility with a preliminary diagnosis of pneumonia of an unidentified etiology in Wuhan China. Initial reports forecast the inception of a possible Coronavirus outburst, given the estimate of a reproduction number for the 2019 Novel (New) Coronavirus (COVID-19, approved by WHO on the day of Feb 11, 2020). ${ }^{16,22,24}$ Ecological factors such as temperature and moisture play a significant role in the 
advancement and transmission of severe acute respiratory syndrome (SARS)-CoV infection with the virus holding its viability for about 5 days at temperatures of $22^{\circ} \mathrm{C}$ to $25^{\circ} \mathrm{C}$ and virtual humidity $(\mathrm{VH})$ of $40 \%$ to $50 \%$. Higher temperatures and higher $\mathrm{RH}\left(38^{\circ} \mathrm{C}\right.$, and $\left.>95 \% \mathrm{RH}\right)$ have been found to decrease virus capability. ${ }^{16,22}$ From the daily health care services that are being interrupted by coronavirus disease 2019 (COVID-19) in Africa is childhood immunization. Its disruption increases the jeopardy of epidemics of vaccinepreventable diseases, which possibly rise the child mortality. ${ }^{1,21}$ Coronavirus disease 2019 is a respiratory disease instigated by a novel virus termed as severe acute respiratory syndrome coronavirus 2 (SARS-CoV-2) and it is so-called 2019 Novel (New) Coronavirus by WHO on Feb 11, 2020. The outburst of this disease was initially reported at the end of December 2019 in Wuhan, China and on March 13, 2020, in Ethiopia Addis Ababa who come from Japan. The virus can blowout from person to person via droplets or unclean surfaces and the maturation date is ranged from 2 to 14 days. ${ }^{1,2}$

Globally Due to COVID-19, the person unable to get healthcare service for unvarying needs, like antenatal care, newborn immunization, etc. ${ }^{20}$ Today about 3.5 million children are dying annually in developing countries from three of the expanded program of immunization target disease, namely measles pertussis, and neonatal tetanus. It is known that children are omitted out on critical vaccines since of COVID-19. Vaccination promotions have been suspended following social separation measures, raising the danger of disease outbreaks. Decrease in routine immunization coverage, particularly if this continues means that many children will be unvaccinated or under-vaccinated, putting their lives at risk of vaccine-preventable diseases. ${ }^{12,20,22}$ From the routine health services that are being interrupted by coronavirus disease (COVID-19) in Africa is childhood immunization. Its interruption increases the risk of epidemics of vaccine-preventable diseases, which could increase child mortality. Consequently, policymakers must rapidly ascertain vigorous and context-specific tactics to promptly scaleup routine immunization to alleviate the impression of COVID-19 on their national immunization performance. To succeed this, we put forward an archetype transference towards systems thoughtful and the use of execution science in immunization policymaking. ${ }^{1,14}$ As much as my knowledge is concerned, studies in the area as well as in the country are limited. So this study very helps full for the scaling up of immunization of a child even if there is a fear of COVID-19.

\section{Method}

A cross-sectional community-based survey supplemented by qualitative Design was conducted in southwest region to assess the incomplete immunization, challenges during COVID-19, and associated factors among children aged 10-23 months from September two to October twenty-one, 2020. All households with children aged 10-23months residing in southwest Ethiopia were the target inhabitants. The household with children in the age range of 10-23 months in the randomly selected zone was the study population. The sampling unit and study units were households and individuals, respectively. The children with their mother or caregivers in southwest Ethiopia during the data collection were included in the study and Mother/ caregivers unable to communicate verbally in the absence of a translator were left out from the study.

The sample size was calculated with both factors and percentages. From all calculated sample sizes the largest one was 1034 but 1300 is taken as the final size due to the final cluster sampling method of the sampling procedure used. From 15 zonal administrations of South Nation Nationality and people region, 7 of them were selected as a cluster. Finally, the eligible household in each zone was traced with the help of health extension workers. In households with more than one eligible child, only one child was included in the study by lottery method. Sample to detailed interview was nominated with the nonprobability purposive sampling method. A total of 10 detailed interviews were accompanied amongst caregiver mothers, fathers, besides priests in Southwest Ethiopia. The dependent variable of the study was immunization status and the independent variables were Sociodemographic features, obstetric characteristics, and health-related factors. The questionnaire was revised and adjusted from the Ethiopian EPI Survey and EDHS, ${ }^{9,10}$ and other interrelated previous studies. ${ }^{3,13,23}$ Twenty nurses and midwifery for data collectors and eight public health supervisors were recruited. Finally, the data were collected by head-on and detailed interviews for quantitative and qualitative data, respectively. A detailed interview was implanted for collecting qualitative data. The detailed interview contained an unrestricted question about the challenge of EPI. The discussions were documented suitably by participant words, and the participants' dialogue was recorded by tape. Finally, their dialogue was transcribed into English words.

\section{Operational and Term Definition}

A fully immunized: a child aged 10 to 23 months old who received one BCG, at least three doses of PENTA-VALENT, 
oral poliovirus, pneumococcal conjugated vaccine (PCV); two doses of rotavirus, and 4 doses of polio vaccine and measles. ${ }^{7}$

Partially/incomplete immunized: child who misses at least one dose of thirteen vaccines. ${ }^{18}$

\section{Result}

\section{Socio-Demographic Characteristics of a Women or Caregivers in Southwest Ethiopia}

The average age of the respondents were $37.5 \pm \mathrm{SD}$ of 2.5 years with a range of 15 to 45 years and the average number of children per household was 3.5 with SD of 1.2
Regarding occupation, more than $85 \%$ of a caregiver were housewife, and Majority of the respondents 1116 $(85.8 \%)$ were married whereas the remaining $14.2 \%$ were widowed, divorced, and single (Table 1).

\section{Place of Delivery and Utilization of Health Service Among the Women Having Children Aged 10-23 Month During COVID-19}

Among the respondents about 753 (57.9\%) of them were explain that other health service care like immunization, family planning, labor, and delivery, as well

Table I Socio-Demographic Characteristics of Mothers or Caregivers Having Children Aged I0-23 Month in Southwest Ethiopia 2020

\begin{tabular}{|c|c|c|c|}
\hline Variables & Category & Frequency & Percentage \\
\hline \multirow[t]{3}{*}{ Age } & $15-25$ & 475 & $36.5 \%$ \\
\hline & $26-35$ & 652 & $50.2 \%$ \\
\hline & $36-45$ & 173 & $13.3 \%$ \\
\hline \multirow[t]{5}{*}{ Maternal education } & Unable to read and write & 551 & 42.4 \\
\hline & Able to read and write & 34 & 2.6 \\
\hline & Primary school & 328 & 25.2 \\
\hline & Secondary school & 329 & 25.3 \\
\hline & Diploma, degree and above & 58 & 4.5 \\
\hline \multirow[t]{4}{*}{ Occupation of the caregiver/mothers } & Housewife & 1109 & 85.3 \\
\hline & Merchant & 95 & 7.3 \\
\hline & Private and government employee & 35 & 2.7 \\
\hline & Daily labor and students & 17 & 4.7 \\
\hline \multirow[t]{4}{*}{ Marital status } & Single & 43 & 3.3 \\
\hline & Married & 1116 & 85.8 \\
\hline & Windowed & 105 & 8.1 \\
\hline & Divorced & 36 & 2.8 \\
\hline \multirow[t]{4}{*}{ Religion } & Orthodox & 811 & 62.4 \\
\hline & Muslim & 75 & 5.8 \\
\hline & Protestant & 393 & 30.2 \\
\hline & Catholic & 21 & 1.6 \\
\hline \multirow[t]{4}{*}{ Ethnicity } & Bench & 744 & 57.2 \\
\hline & Oromo & 282 & 21.7 \\
\hline & Amhara & 239 & 18.4 \\
\hline & Sheko & 35 & 2.7 \\
\hline
\end{tabular}




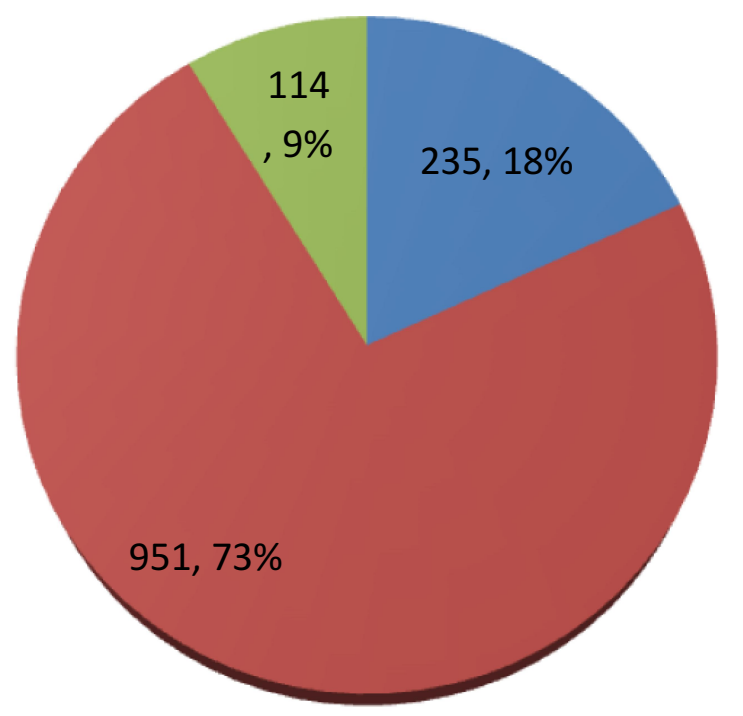

at home $\quad$ Health center $\quad$ Hospital

Figure I A place of delivery of the women having children aged 10-23 month in southwest Ethiopia in 2020.

other medical cares were given together with the care COVID-19 or they do not understand the separation care of COVID-19 and other health services. Near half of the respondents, $450(34.6 \%)$ regretted visiting the health facility for the fear of COVID-19 transmission by the health professionals (Figure 1).

\section{Health Facility and Obstetric Characteristics of the Respondents in Southwest Ethiopia 2020}

Most of the caregivers 953 (73.3\%) spent time/waiting after coming to the health facility was less than 10 minutes. The remaining $24 \%, 1.2 \%$, and $1.5 \%$ were 10 to 15.15 to 30 and greater than a 30 -minute wait for getting immunization, respectively (Figure 2Figure 5Figure 6Figure 7).

More than $88 \%$ of the participants/caregiver take their child to the health facility when their child was being sick but about $8 \%$ and $2 \%$ of the caregiver take their child to a traditional place and treat at home, respectively (Figure 3).

Among the participants, only 905 (69.9\%) had antenatal care during their pregnancy, the reaming 395 $(30.4 \%)$ were giving birth without antenatal care (Figure 4).

\section{Immunization Status of Children Aged from 10 to 23 Months in Southwest Ethiopia 2020}

The prevalence of incomplete immunization was found to be $809(62.2 \%)(95 \%$ CI: $59.5,64.8)$ of the total respondents1110 (85.4\%) of them took both BCG and OPV vaccine, from 1110 BCG started children only 798 (71.8\%) of the children complete their immunization. Of the total 1300 children, $190(14.6 \%)$ of them were not taking any vaccine at all. Overall $1088(83.7 \%)$ of them received both PCV one and Penta one, 1082 (83.2\%) received rota1 and $798(61.4 \%)$ received measles vaccine. The coverage rate was a decline for the consecutive dose, such as OPV zero (85.4\%) to OPV three (73.7\%), both Penta and PCV one (83.7\%) to Penta and PCV three (71.9\%).

Dropout rate: the overall dropout rate of immunization in the zone was BCG to measles, $\frac{B C G-\text { measles, }}{B C G} * 100=$ $\frac{1110-798}{1110} * 100=28 \%$, and the dropout rate of each subsequent vaccine was $13.6 \%$ for OPV0 to OPV3, $12.2 \%$ for PCV1 to PCV3 and $14 \%$ for pena1 to penta3 for more detail see on (Figures 5-7)

\section{In-Depth/Detail Interview Finding}

Theme I: Fear of COVID-19 Transmission During Transportation to a Health Facility

The rural mother of the child complains that during the transportation to the health facility we are asked to wear a face mask without the access of a face mask in the nearby area $(20,34,36,40$, year's old rural mothers). Even if we wear a face mask we do not trust that will protect our child from COVID-19 and ourselves (26 and 32 years old

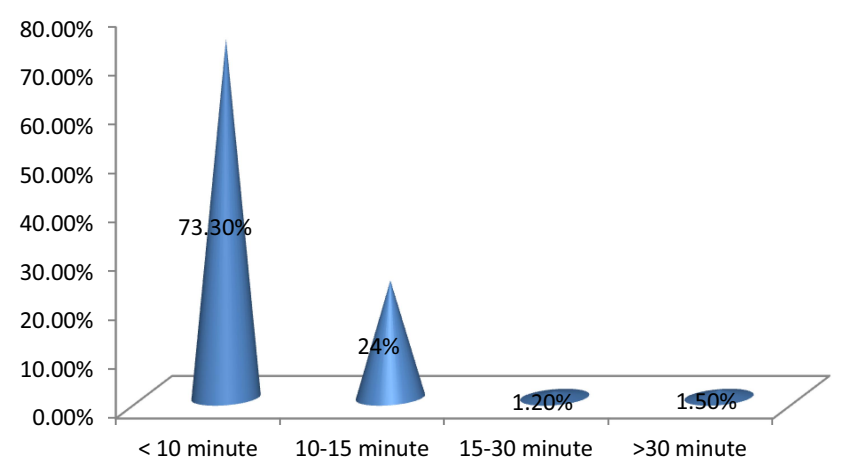

Figure 2 The time waiting of the women at a health facility for immunized their child in southwest Ethiopia 2020. 


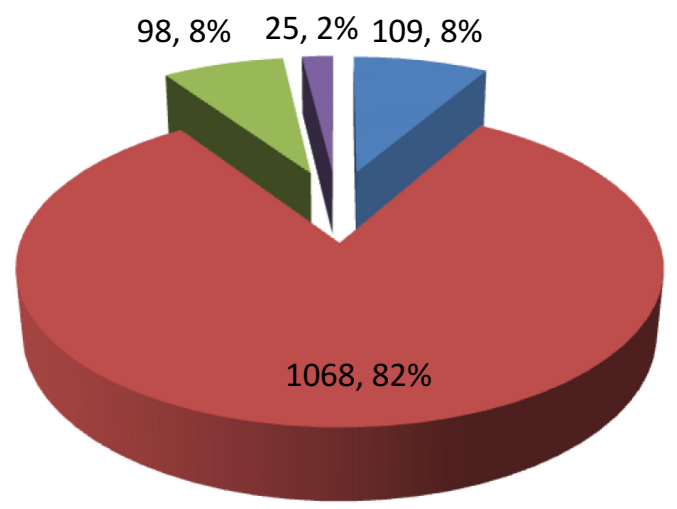

$\square$ Health post
$\square$ Religion or traditional place $\square$ Self-treatment at home

Figure 3 A place of health care when the child was being sick in southwest Ethiopia 2020.

mothers). As we hear that the virus stays everywhere such as on clothes, metal, and different surfaces, we fear the surface of the bus for contaminated with COVID-19 (35.37, 40 and 46 years old fathers of the children).

Fear of screening by temperature regardless of other cause of raising the temperature and took us to quartile and Isolation areas without evidence of COVID-19 and doubling up of transportation fee because of COVID19 (30, 42, 45. And 47 years old priests).

\section{Theme 2: Challenges in the Health Facility and COVID-19 Transmission}

Considering the health professions as a career of COVID-19 and the may transmit these COVID-19 to our children during immunization $(27,32,35,43$ years old priests). We understand that the immunization

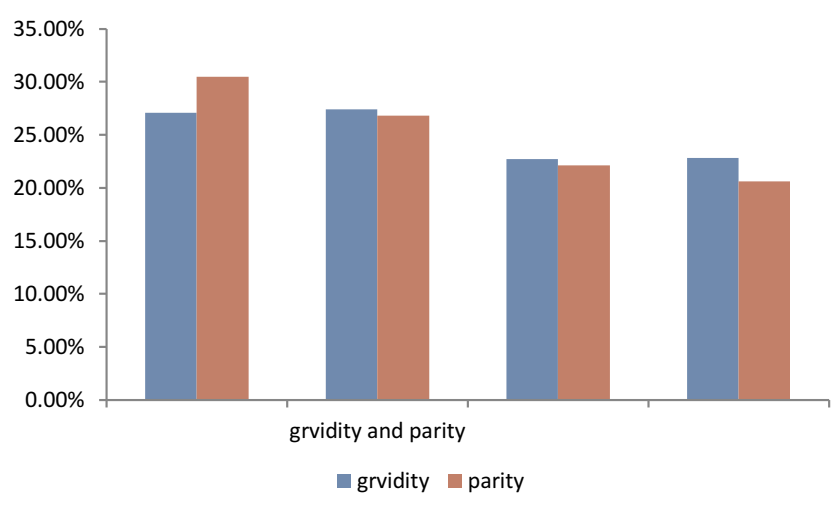

Figure 4 The gravidity of the caregiver having children aged 10-23 month in southwest Ethiopia 2020. service of the children was given together with the care of COVID-19 in the health facility, so we assume there was a high transmission of COVID-19 during getting the service and as the come up time at the health institution was too long to get the service, person to person transmission is very high at a health facility (this is the idea of all mother of the children). During waiting time at the health facility we fear individual-toindividual transmission of COVID-19 because the waiting area in the health facility was very condensed and not ventilated $(30,29,34$, and 41 years old father of the children).

\section{Factors Associated with Immunization Status of Children Aged 10-23 Months During COVID-19}

Bivariate logistic regression analysis shows that waiting time, educational status, delivery place, considering COVID-19 and other service is given at the same unit, fear of COVID-19 from health profession and means of transportation were all significantly accompanying with incomplete immunization at p-value 0.05. From all variables on marital status was not significantly associated. However, on multivariable analysis except for marital status and means transportation, all the variables were identified as independently significant associated factors with incomplete immunization.

The women waiting time more than 30 minutes at a health facility for immunization were $96 \%$ more likely to have incomplete immunization than waiting less than 30 minutes $(\mathrm{AOR}=04,95 \% \mathrm{CI} 0.0001,0.004)$. The odd of incomplete immunization of the children was 2.34 times higher in the women who deliver at home than deliver at a health facility (AOR $=2.336,95 \%$ CI 4.96, 6.089). The child who was born from women who cannot read and write were 5.08 times incompletely immunized than the child born from educated women (diploma, degree, and above $)(\mathrm{AOR}=5.08,95 \% \mathrm{CI} 2.31,11.14)$. The women who cannot understand the separation care of CIOVID 19 and other health service had 3.62 times incompletely immunized child than who understand the separation care of COVID-19 and another health service (AOR=3.62,95\% CI 1.72,7.64). The odd of incomplete immunization of a child for the women who fear health professions as a source of COVID-19 was 2.85 times higher than did not fear the health profession $(\mathrm{AOR}=2.85,95 \% \mathrm{CI}$ 1.38,5.9) (Table 2) 


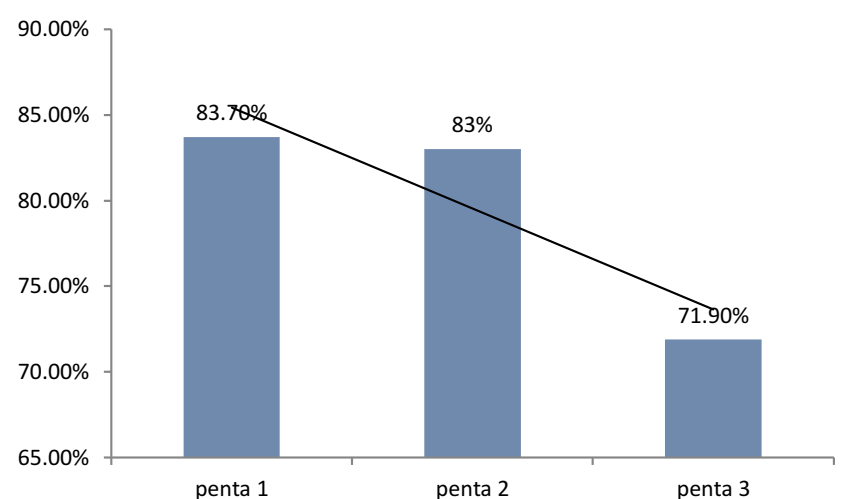

Figure 5 The trends of subsequent immunization of Penta vaccine during COVID19 in southwest Ethiopia 2020.

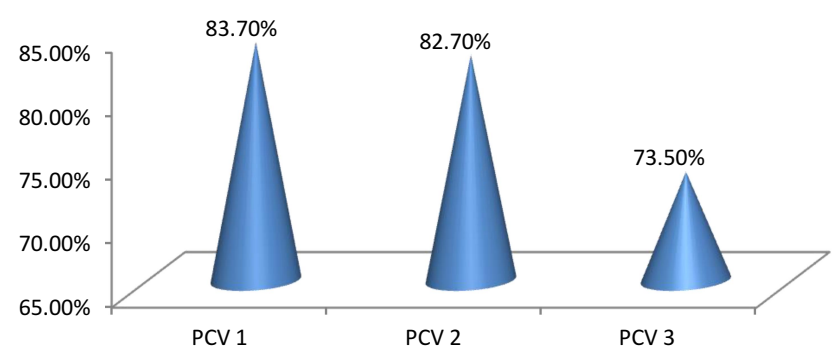

Figure 6 The subsequent immunization of PCV vaccine during COVID-19 in southwest Ethiopia 2020.

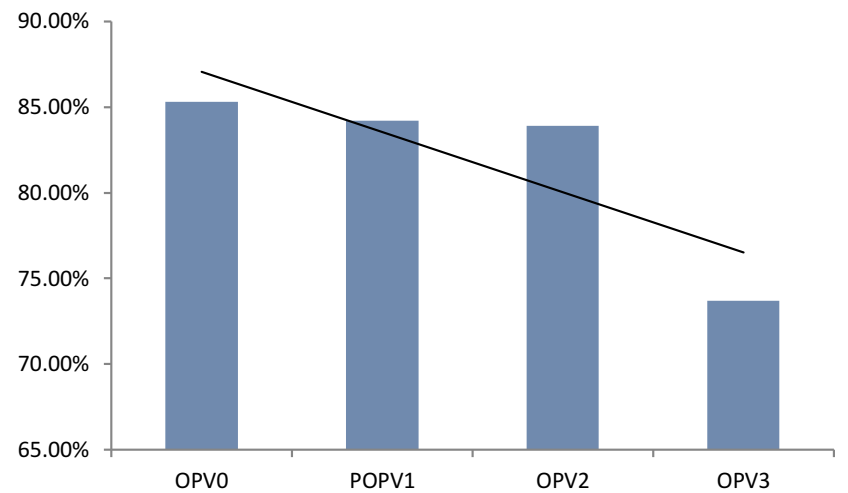

Figure 7 The trends of subsequent immunization of OPV vaccine during COVID19 in southwest Ethiopia 2020.

\section{Discussion}

This is a cross-sectional community-based survey supplemented by a qualitative study that has attempted to determine Immunization status and challenges during COVIODN 19 and Accompanying Factors among Children Aged 10-23 Months.

The percentage of incomplete immunization among children aged from 10 to 23 months in this study was found to be $809(62.2 \%)(95 \%$ CI: $59.5,64.8)$. This study is in similar with the study done by further analysis of 2016 EDHS $(61.7 \%)$ and the finding in Sierra Leone ranged from $(50 \%$ to $85 \%)$. ${ }^{4,17}$ This consistency may be the current immunization practice of the women is regretted to the pervious poor immunization intention of the women. Because before 5 years back the immunization thinking of the women is so poor due to miss understanding of the advantage of immunization.

The outcome of this study was greater than the study done in a different part of Ethiopia like in Wonago Gedo (47.6.\%), Deber Markos (28.3\%), northwest Ethiopia (41.6\%), Gondar (24.3\%), Woldiya (11.3\%), Sekota (22.6\%), systematic and meta-analysis of immunization from 2003 to 2019 in Ethiopia (41.8\%) another systematic and meta-analysis were done in Ethiopia 2020 (53\%), at a tertiary-care hospital (University College of Medical Sciences and Guru Tegh Bahadur Hospital, New Delhi, India (48\%) and at Indonesia (2008-2013): a multilevel analysis $(38.13 \%){ }^{3,5-8,11,15,19,23}$ The possible explanation for this can be almost all women have a misunderstanding of about the separation care of COVID-19 and other services like immunization, cost of transportation doubling up and fear of health professionals as a source of COVID-19 was the possible reason to decline the immunization as evidenced by an in-depth interview.

In this study, the women waiting more than 30 minutes at a health facility for immunization were $96 \%$ more likely to have incomplete immunization as compared with those women waiting less than 30 minutes $(\mathrm{AOR}=04,95 \% \mathrm{CI}$ $0.0001,0.004)$. The reason may be as the women are busy in their duty; being staying more time in a health facility for immunization program will disappoint the women to come back the next immunization schedule. Not only this but also as waiting time increase, overcrowding in waiting area and stress will increase; this will be high risk for the transmission of COVID-19. As result of the above possible obstacle the women may discontinuous from the immunization program. This is supported by the study done in Sekota zuria district, Gondar city administration, Deber Markos town, and in North West Ethiopia. 3,6,7,19 The odd of incomplete immunization of the children was 
Table 2 Multi-Variate Logistic Regression of Factors for Incomplete Immunization of Children in Southwest Ethiopia 2020

\begin{tabular}{|c|c|c|c|c|c|}
\hline & & \multicolumn{2}{|c|}{ Status of Immunization } & \multirow[t]{2}{*}{ COR $(95 \% \mathrm{Cl})$} & \multirow[t]{2}{*}{$\operatorname{AOR}(95 \% \mathrm{Cl})$} \\
\hline & & $\begin{array}{r}\text { Incomplete } \\
\mathbf{N} \%\end{array}$ & $\begin{array}{r}\text { Complete } \\
\mathbf{N} \%\end{array}$ & & \\
\hline \multirow[t]{2}{*}{ Waiting time at the health facility } & $\begin{array}{l}\text { Less than } \\
30 \text { minute }\end{array}$ & $48 I(98.0 \%)$ & $46(5.7 \%)$ & I & \\
\hline & $\begin{array}{l}\text { Greater than } \\
30 \text { minute }\end{array}$ & $10(2.0 \%)$ & $763(94.3 \%)$ & $0.02(0.001,0.003)$ & $0.04(0.000 I, 0.004)$ \\
\hline \multirow[t]{2}{*}{ Marital status } & Single & $63(12.8 \%)$ & $51(31.0 \%)$ & I & \\
\hline & Married & $428(87.2 \%)$ & $558(69.0 \%)$ & $0.56(0.24,0.44)$ & $1.354(0.630,2.908)$ \\
\hline \multirow[t]{2}{*}{ Means of transportation to a health facility } & On foot & $382(77.8 \%)$ & $515(63.7 \%)$ & $2(1.55,2.59)$ & $2.128(0.065,4.250)$ \\
\hline & $\begin{array}{l}\text { By } \\
\text { transportation }\end{array}$ & $109(22.2 \%)$ & $294(36.3 \%)$ & I & \\
\hline \multirow[t]{2}{*}{ Place of delivery } & $\begin{array}{l}\text { At Health } \\
\text { Facility }\end{array}$ & $83(16.9 \%)$ & $176(21.8 \%)$ & I & \\
\hline & At home & $408(83.1 \%)$ & $633(78.2 \%)$ & $1.37(1.02,1.83)$ & $2.336(4.96,6.089)$ \\
\hline \multirow[t]{4}{*}{ Educational status } & $\begin{array}{l}\text { Unable to read } \\
\text { and write }\end{array}$ & $221(45.0 \%)$ & $330(40.8 \%)$ & $1.42(1.08,1.87)$ & $5.08(2.31,11.14)$ \\
\hline & Read and write & $26(5.3 \%)$ & $8(1.0 \%)$ & $6.9(3.03,15.66)$ & $3.46(1.31,12.85)$ \\
\hline & $\begin{array}{l}\text { Primary and } \\
\text { secondary } \\
\text { school }\end{array}$ & $120(24.4 \%)$ & $208(25.7 \%)$ & $1.22(1.20,1.67)$ & $3.54(1.59,7.89)$ \\
\hline & $\begin{array}{l}\text { Diploma, degree } \\
\text { and above }\end{array}$ & $124(25.3 \%)$ & $263(32.5 \%)$ & I & \\
\hline \multirow{2}{*}{$\begin{array}{l}\text { Do you think that COVID-19 care is given } \\
\text { together with other health services }\end{array}$} & Yes & $307(62.5 \%)$ & $446(55.1 \%)$ & $1.36(1.08,1.71)$ & $3.62(1.72,7.64)$ \\
\hline & No & $184(37.5 \%)$ & $363(44.9 \%)$ & I & \\
\hline \multirow{2}{*}{$\begin{array}{l}\text { Do you fear immunization provider health } \\
\text { professionals as a source of COVID-19 }\end{array}$} & Yes & $216(44.0 \%)$ & $234(28.9 \%)$ & $1.93(1.53,2.44)$ & $2.85(1.38,5.9)$ \\
\hline & No & $275(56.0 \%)$ & $575(71.1 \%)$ & I & \\
\hline
\end{tabular}

2.34 times higher in the women who deliver at home as compared with the women delivered at a health facility (AOR $=2.336,95 \%$ CI 4.96, 6.089). The possible explanation may be the women deliver at health facilities have more information about the importance of immunization than home-delivered women. They also are educated and have a good attitude and knowledge for free utilization of health services. This is supported by a study done in Sekota zuria District, further analysis of EDHS 2016, and Northwest Ethiopia ${ }^{6,17,19}$ and on the other hand not supported by the findings in Wonago Gedo zone, Deber Markos town. ${ }^{7,8}$

The child of uneducated women were 5.08 times more incompletely immunized as compared to the child of educated women (diploma, degree, and above) ( $\mathrm{AOR}=5.08,95 \%$ CI $2.31,11.14$ ). The possible reason is as the women are educated; they easily identify the possible vaccine-preventable disease and easy approach to a health facility as well there is no misperception regarding health service utilization. This is supported by the finding further analysis of EDHS 2016 and Sekota District $^{6,17}$ but not supported by the study done in Northwest Ethiopia, Deber Markos Town, Wonago District, and Gondar Town. ${ }^{3,7,8,19}$

The women who cannot understand the separation care of CIOVID 19 and other health service had 3.62 times incompletely immunized their child as compared to the women who understand the separation care of 
COVID-19 and other health services (AOR $=3.62,95 \%$ CI 1.72,7.64) and The odd of incomplete immunization of a child for the women who fear health professions as a source of COVID-19 was 2.85 times higher as compared to the women who did not fear the health profession for the source of COVID-19 (AOR $=2.85,95 \% \mathrm{CI}$ $1.38,5.9)$. This is explained as the women did not understand the separation care of COIVID 19 and other health services as well did not aware about phone service of the health facility, they drop out from the service by fearing transmission of COVID-19 between the client and from health professions.

\section{Conclusion}

Based on the finding obtained in this study, the prevalence of incomplete immunization in the South Nation Nationality and People region among children age 10-23 months was very high as compared to other studies.

Variables significantly associated with incomplete immunization among children aged 10-23 months were time waiting at a health facility, place of delivery, educational status of the women, not understanding the separation care of COVID-19 and other health services, fear of health professionals as a source of COVID-19.

\section{Abbreviations}

ANC, antenatal care; BCG, Bacillus Chalmette Guerin; DHS, Demographic and Health survey; DPT, Diphtheria, Pertussis, Tetanus; EDHS, Ethiopian Demographic and Health survey; EPI, Expanded Program on Immunization; HBV, Hepatitis B Virus; HIB, Hemophilic Influenza type $\mathrm{B}$; $\mathrm{MOH}$, Ministry Of Health; OPV, Oral Polio Vaccine; PCV, Pneumococcal Conjugate Vaccine; WHO, World Health Organization; SNNPR, South Nation, Nationality and People Region; COVID-19, coronavirus disease 2019.

\section{Data Sharing Statement}

The data set used and/or investigated during the current study is available from the conforming author on realistic request.

\section{Ethics Approval and Consent to Participate}

Ethical clearance letter was obtained From the Ethical Review Committee of Midwifery, under the delegation of the institutional review board of Mizan Tepi University and submitted to each zonal administrative staffs to obtained permission letter. Then each zonal administrative staff given a written permission letter to the concerned bodies in the study set up. All participants were informed about the purpose of the study before consenting to participate. A Verbal consent form was taken for (mothers' or care givers) age greater than 18 years and separated assent form was taken for mothers' age 18 years and below on behalf of the child aged 10-23 Months before the data collection. The participants' privacy was confidential and anonymous. This study was conducted in accordance with the Declaration of Helsinki.

\section{Acknowledgment}

First and foremost, our heartfelt goes to the Mizan Tepi University research committee for their permission letter and the health science staff for their continuous up keeping. Our thanks likewise go to southwest region administrator and different zones and woreda administrators in southwest Ethiopia for their permission and uninterrupted follow-up and health extension workers for their valuable information and are inside us during the data collection period. Finally, we thank you our data collector and participants for their cooperative and time.

\section{Author Contributions}

All authors made a significant contribution to the work reported, whether that is in the conception, study design, execution, acquisition of data, analysis and interpretation, or in all these areas; took part in drafting, revising or critically reviewing the article; gave final approval of the version to be published; have agreed on the journal to which the article has been submitted; and agree to be accountable for all aspects of the work.

\section{Funding}

Any fund or benefits are not received by the authors from industry or elsewhere to undergo this study.

\section{Disclosure}

There are no competing interests declared by the authors in this work.

\section{References}

1. Adamua AA, Rabiu IJ, Habonimanad D, Charles S, Wiysongea BE. Covid-19 and routine childhood immunization in Africa: leveraging systems thinking and implementation science to improve immunization system performance. Int J Infect Dis. 2020;98. 
2. WHO for Africa. The federal ministry of health has confirmed a Coronavirus disease (Covid-19) case in Addis Ababa, Ethiopia. 2020.

3. Assimamaw NT, Yismaw AE, Bayu NH, Mekonen SS. Incomplete childhood vaccination and associated factors among children aged 12-23 months in Gondar City Administration, Northwest, Ethiopia 2018. BMC Res Notes. 2019;12.

4. Buonsenso D, Cinicola B, Kallon MN, Iodice F. Child healthcare and immunizations in Sub-Saharan Africa during the Covid-19 pandemic. Front Pediatr. 2020;8. doi:10.3389/fped.2020.00517

5. Eshete A, Shewasinad S, Hailemeskel S. Immunization coverage and its determinant factors among children aged 12-23 months in Ethiopia: a systematic review, and meta-analysis of cross-sectional studies. $B M C$ Pediatr. 2020;20:283. doi:10.1186/s12887-020-02163-0

6. Girmay A, Dadi AF. Full immunization coverage and associated factors among children aged 12-23 months in a hard-to-reach areas of Ethiopia. Int J Pediatr. 2019;2019:1924941. doi:10.1155/2019/ 1924941

7. Gualu T, Dilie A. Vaccination coverage and associated factors among children aged 12-23 months in Debre Markos Town, Amhara Regional State, Ethiopia. Adv Public Health. 2017;2017:5352847. doi: $10.1155 / 2017 / 5352847$

8. Hailu S, Astatkie A, Johansson KA, Lindtjørn B, Angelillo IF. Low immunization coverage in Wonago District, Southern Ethiopia: a community-based cross-sectional study. PLoS One. 2019;14: e0220144. doi:10.1371/journal.pone.0220144

9. Federal Ministry of Health. Comprehensive multi-year plan 2016-2020. 2015.

10. Immunization manual for health workers. 2012.

11. Holipah AM, Kuroda Y, Kuroda Y. Determinants of immunization status among 12- to 23-month-old children in Indonesia (2008-2013): a multilevel analysis. BMC Public Health. 2018;18:288. doi:10.1186/ s12889-018-5193-3

12. Kroumpouzos G, Gupta M, Jafferany M. Covid-19: a Relationship to Climate and Environmental Conditions?. Derm Ther. 2020;e13399.

13. Kumar D, Aggarwal A, Gomber S. Immunization status of children admitted to a Tertiary-Care Hospital of North India: reasons for partial immunization or nonImmunization. $J$ Health Popul Nutr. 2010;28:300-304. doi:10.3329/jhpn.v28i3.5560
14. Liu Y, Gayle AA, Wilder-Smith A, Rocklöv J. The reproductive number of Covid-19 is higher compared to Sars Coronavirus. J Travel Med. 2020.

15. Nour TY, Farah AM, Ali OM, Abate KH. Immunization coverage in Ethiopia among 12-23 month old children: systematic review and meta-analysis. BMC Public Health. 2020;20:1134. doi:10.1186/ s12889-020-09118-1

16. Rothan HA, Byrareddy SN. The epidemiology and pathogenesis of Coronavirus disease (Covid-19) outbreak. J Autoimmun. 2020;109:102433. doi:10.1016/j.jaut.2020.102433

17. Tamirat KS, Sisay MM. Full immunization coverage and its associated factors among children aged 12-23 months in Ethiopia: further analysis from the 2016 Ethiopia Demographic and Health Survey. BMC Public Health. 2019;19:1019. doi:10.1186/s12889-019-7356-2

18. Tesfaye TD, Temesgen WA. Vaccination coverage and associated factors among children aged 12-23 months in Northwest Ethiopia. Human Vaccines Immunotherap. 2018;14:2348-2354.

19. Tesfaye TD, Temesgen WA, Kasa AS. Vaccination coverage and associated factors among children aged $12-23$ months in Northwest Ethiopia. Hum Vaccin Immunother. 2018;14:2348-2354. doi:10.1080/21645515.2018.1502528

20. UNICEF/UNI315081/Yuwei. The impact of Covid-19 on routine vaccinations reflections during world immunization week 2020. 2020.

21. WHO. Progress and challenges with achieving universal immunization coverage. 2020

22. Z X, Shi L, Wang Y, et al. Pathological findings of Covid-19 associated with acute respiratory distress syndrome. Lancet Respir Med. 2020;8:420-422. doi:10.1016/S2213-2600(20)30076-X

23. Mamo Abebe MWKY, Zemariam AB, Shewangashaw NE. Coverage, opportunity, and challenges of expanded program on immunization among 12-23-month-old children in Woldia Town, Northeast Ethiopia, 2018'. Hindawi. 2018;12.

24. Zheng YY, Ma YT, Zhang JY, Xie X. Covid-19 and the cardiovascular system. Nat Rev Cardiol. 2020;17:259-260. doi:10.1038/ s41569-020-0360-5
Pediatric Health, Medicine and Therapeutics

\section{Publish your work in this journal}

Pediatric Health, Medicine and Therapeutics is an international, peerreviewed, open access journal publishing original research, reports, editorials, reviews and commentaries. All aspects of health maintenance, preventative measures and disease treatment interventions are addressed within the journal. Practitioners from all disciplines are invited to submit their work as well as healthcare researchers and patient support groups. The manuscript management system is completely online and includes a very quick and fair peer-review system. Visit http://www.dovepress.com/testimonials.php to read real quotes from published authors. 